\section{The oral management of patients who have received radiotherapy to the head and neck region}

\author{
A. Ray-Chaudhuri, ${ }^{1,2}$ K. Shah ${ }^{* 1}$ and R. J. Porter ${ }^{1}$ \\ VERIFIABLE CPD PAPER
}

IN BRIEF

- Summarises the effects of radiation and radiotherapy on human tissues.

- Lists the common oral side-effects of radiotherapy to the head and neck region.

- Outlines the oral management and suggests advice for affected patients to reduce undesirable sequelae.

Several thousand patients are diagnosed annually with head and neck cancer (HANC) in the United Kingdom. This represents a significant proportion of all cancers that are diagnosed and a common treatment modality for this is radiotherapy to the head and neck region. Radiotherapy can be highly successful in managing HANC but also has several side-effects in the oral cavity and associated structures. These sequelae present considerable short and long-term problems for dental professionals involved in the care of HANC suffers.

\section{INTRODUCTION}

Head and neck cancer (HANC) is a collective term to describe a group of diverse malignant tumours affecting the upper aero-digestive tract. Indeed the term encompasses at least 30 different disease sites as described by the World Health Organization (WHO) in their International classification of diseases and health related problems (ICD 10). ${ }^{1}$ The term HANC typically excludes other malignancies that may affect similar anatomical areas for example, brain tumours, skin tumours or haematogenic malignancies.

A common site for the primary disease is the oral cavity, which represents over $40 \%$ of global cases. Other common sites for the primary tumour include the pharynx, larynx, nasal cavity and paranasal sinuses. The vast majority of these cancers are squamous cell carcinomas (SCCs) with other histological types being individually rare.

Head and neck cancers represent 6\% of all cancers that are diagnosed in the world. ${ }^{2}$ Annually there are approximately 670,000 new cases that are diagnosed and 350,000 deaths worldwide. More than

'Restorative Dentistry, St George's Hospital, London, SW17 00T; ${ }^{2}$ Restorative Dentistry, King's College Dental Hospital, Bessemer Road, London, SE5 9RS

${ }^{*}$ Correspondence to: Kewal Shah

Email:kewal.shah@nhs.net

\section{Refereed Paper}

Accepted 7 December 2012

DOI: $10.1038 /$ sj.bdj.2013.380

${ }^{\bullet}$ British Dental Journal 2013; 214: 387-393 two thirds of new cases are reported in males although this disparity between genders has been slowly reducing over the last few decades.

The exact prevalence and incidence of HANC in the UK is hard to ascertain. This is because of a combination of incomplete reporting and fragmentation of the key data, that is, some data sets record HANC as a whole while others report data by histology or anatomical sites affected. Nonetheless estimates can be obtained from key documents.

In a one-year period the data for head and neck oncology (DAHNO) recorded 6,133 new diagnoses of HANC in England and a further 325 diagnoses in Wales. ${ }^{3}$ In a similar period there were another 1173 new reported cases in Scotland. ${ }^{4}$ This made HANC in Scotland the fourth most common cancer in men, the tenth most common in women and the fifth most common type of cancer overall.

The data also illustrates marked regional differences for HANC incidence and survival in the UK. For example, the incidence of HANC in males in the North Thames area is half the incidence of HANC in males in Scotland. ${ }^{5}$ Similarly the one- and five-year patient survival figures for HANC are poorer in Scotland, Wales and Northern Ireland compared to more affluent regions of England.

There are many different modalities available for treating cancers of the head and neck depending on parameters such as the site, TNM stage, grade, co-morbidities etc. Although surgery is the oldest and most common form of treatment, especially in the oral cavity, it may not be indicated or even possible for some forms of HANC.

Radiotherapy (radiation therapy) is defined as "the use of high-energy radiation from X-rays, gamma rays, neutrons, protons, and other sources to kill cancer cells and shrink tumours. ${ }^{6}$ It was used to treat patients diagnosed with cancer soon after X-rays were first discovered by Wilhelm Conrad Röntgen in 1895.

Modern radiotherapy has been shown to have similar success in treating HANCs when compared to surgery if the lesion is at an early stage. Indeed, radiotherapy is now considered to be superior to surgery in many HANCs and is the primary treatment modality in patients with cancers of the pharynx and larynx. Radiotherapy may also be used in combination with surgery to improve clinical outcomes especially if a clear margin of healthy tissue has not been excisable around the tumour or where there is involvement of the regional lymph nodes. Finally, radiotherapy may be used alone or in combination with chemotherapy (chemo-radiotherapy) as palliative treatment in patients with advanced disease and/or otherwise unmanageable symptoms for example, pain control. ${ }^{7}$

The restorative dentist is an integral part of a wider multi-disciplinary team (MDT) whose remit is to diagnose, manage and rehabilitate patients who have been 
Table 1 The core clinical members of the multi-disciplinary team (MDT) for the management of HANC as advised by the National Institute of Health and Clinical Excellence (NICE)

\section{HANC surgeons}

Clinical oncologist

Restorative dentist

Pathologist

Radiologist

Clinical nurse specialist

Speech and language therapist

Dietitian

Palliative care specialist

diagnosed with HANCs (Table 1). ${ }^{8,9}$ Their role is to work with other team members to provide prompt advice and treatment at all stages of the patient pathway from diagnosis to discharge. ${ }^{10,11}$ Indeed the restorative dentist is often the clinician who will be seeing the patient long after their discharge from the care of the surgical and oncology team.

This paper outlines the dentist's role in the management of these patients from pre-radiotherapy dental assessment to the management of the radiogenic oral side-effects.

\section{HOW RADIOTHERAPY WORKS}

Ionising radiation has the potential to cause damage to any component of a cell. The therapeutic effects of ionising radiation are affected through direct damage to the DNA of the cell or indirectly by damage to the DNA caused by free radicals released by the interaction of water and radiation. Once irreparable damage has been caused to the single or double stranded DNA the cell loses its ability to sustain cell division. If all the cells of a tumour are sterilised and lose their proliferative potential then the tumour will be cured. If partial sterilisation has occurred then the tumour will be in stasis or regression but will have the potential to re-grow when the cells regain their proliferative potential.

This damage is not, however, limited to cancer cells and thus radiotherapy has significant effects on the integrity and function of healthy cells. Similar to the effects on cancerous cells the injury to healthy cells is dose related. This dose-response relationship in healthy tissue is fundamentally dependent on the survival of the tissue's stem cells and the immediacy of the response is related to the turnover of

Table 2 Common oral fungal, bacterial and viral infections seen in HANC patients treated

with radiotherapy

\begin{tabular}{|l|l|l|}
\hline Fungal infections & Candidiasis, aspergillosis, blastomycosis etc \\
\hline Bacterial infections & Odontogenic & Caries, pulpal infection, pericorinitis \\
\hline & Periodontal & Necrotising ulcerative gingivitis or periodontitis \\
\hline & Other & Bacterial sialoadenitis \\
\hline Viral infections & Herpes simplex, zoster, cytomegalovirus etc \\
\hline
\end{tabular}

Table 3 A summary of the suggested pathophysiology of osteoradionecrosis of the jaws (ORNJ)

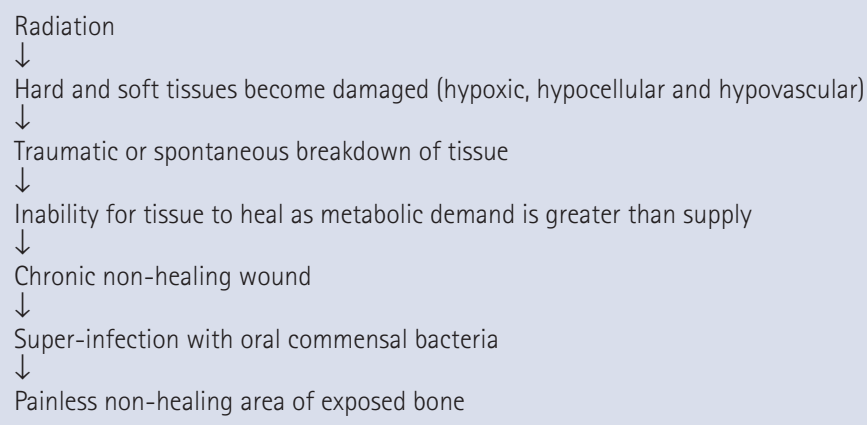

its mature cells. For example, epithelial tissues such as the oral mucosa have a rapid cell turnover and thus frequently exhibit acute effects, often within days. Organs or tissues with a slower cell turnover for example, bone, tend to experience late effects, which can take months or years to manifest. It is often the risk of severe late effects that limits the dose of radiotherapy.

\section{HOW RADIOTHERAPY AFFECTS THE ORAL CAVITY}

A large proportion of HANC patients present with a primary tumour in the oral cavity. Many of these tumours will be removed surgically with or without surgical reconstructive. Some of these patients, however, will not be able to have complete removal of their tumour or will not be fit for surgery and thus will require radiotherapy to the oral cavity.

These patients receive a significant dose of ionising radiation to the oral cavity (60 Gy plus) and often present with significant acute and late side-effects that require the help of a dentist.

There is a larger cohort of patients who also receive radiotherapy due to a primary tumour in another part of the head and neck area but have the side-effects of this presenting in the oral cavity.

The oral sequelae of radiotherapy to the head and neck region are well documented and include the following. ${ }^{12}$

\section{Mucositis}

Mucositis can simply be described as an inflammation of the mucosa and can occur anywhere in the alimentary canal. Ionising radiation is known to commonly cause this, especially in the oral mucosa where it is described as radiation-induced oral mucositis. Patients who receive radiotherapy for an oral or oro-pharyngeal lesion inevitably develop oral mucositis, which can be severely debilitating and in severe cases can limit the radiation dose. It is now believed to be caused by radiationinduced damage to the basal cells of the oral epithelium rather than direct superficial cell injury. Clinically oral mucositis follows a relatively predictable path presenting as erythema, atrophy, ulceration and eventual healing. The most commonly reported oral areas that are affected are the buccal mucosa, floor of mouth and the soft palate but there are no areas that are immune. It is worthy of note that the affected area may be in the pharynx or upper digestive tract and although not clinically visible may still severely limit a patient's ability to swallow. Oral mucositis usually appears early on in radiotherapy regime and is often the first acute sideeffect. Its early signs are known to appear with as little as 10 Gy cumulative radiation dose, which is often reached within the first week in a standard course of radiotherapy for a HANC (Fig. 1). 
Recent Cochrane collaboration reviews have found that the quality of evidence available for the prevention and treatment of oral mucositis is relatively low. There is some evidence that patients may benefit from the use of ice chips and keratinocyte growth factor (palifermin) in the prevention of oral mucositis and sucralfate to reduce its severity. ${ }^{13}$ Use of a low level laser has also been demonstrated to benefit patients who have severe mucositis and may reduce the amount of analgesia required. ${ }^{14}$

\section{Taste disturbance}

Taste disturbance is a commonly reported sequelae of radiotherapy to the head and neck region and effects up to $90 \%$ of patients to some degree. ${ }^{15}$ It is predominantly caused by direct radiation damage to the thousands of taste buds that are distributed around a patient's lips, tongue, oral cavity, pharynx, upper oesophagus and nasal cavity. Further changes in taste perception are caused by a reduction in the quantity and quality of the saliva as well as opportunistic infections as discussed below. Taste disturbance develops early on in the treatment regime and peaks at four to eight weeks (Fig. 2). Taste disturbance can be broadly caused by three phenomena:

1. Hypogeusia - a reduction in overall taste

2. Dysgeusia - a distortion of normal taste. Bitter and salt are the most common tastes that are perceived to be reduced during and after radiotherapy

3. Ageusia - an absence of taste.

Most patients recover their taste perception after their radiotherapy regime has been completed, however, a partial taste disturbance has been reported up to seven years post-treatment. ${ }^{16}$

\section{Opportunistic infections}

The healthy oral cavity is able to support a variety of microbiota with more than 700 taxa isolatable using modern techniques. These are commensal organism but may initiate or progress pathology if there are changes in environmental conditions such as those caused by the direct effects of radiation therapy (on other species) or indirectly (by causing mucositis, hyposalivation etc).
Common opportunistic infections during and after radiotherapy are summarised in Table 2.

\section{Xerostomia and salivary hypofunction}

Salivary gland tumours are relatively rare and constitute only 5\% of all HANCs. These patients are often treated with complete or partial surgical removal and/or radiotherapy and unsurprisingly suffer a degree of salivary hypofunction.

The majority of patients, however, suffer xerostomia or salivary hypofunction due to radiotherapy for cancers of unrelated structures and thus as a direct side-effect of treatment. In low radiation doses (less than $30 \mathrm{~Gy}$ ) it is believed that damage may be reversible although in higher doses (more than 75 Gy) significant degeneration of the acini are seen with concomitant inflammation and fibrosis of the interstitium.

It is worth noting that salivary hypofunction can be described as an objective finding of the reduction in saliva from one or more gland and should be distinguished from xerostomia, which is the subjective feeling of oral dryness regardless of objective findings. ${ }^{17}$

In a recent survey of 75 patients who had completed radiotherapy to the head and neck region more than six months before the study, 70 (93\%) complained of continuing xerostomia and 40 (53\%) complained of severe xerostomia. This questionnaire-based study also found that xerostomia had a significant negative impact on patients' lives including causing 'worry', 'tension' and 'depression. ${ }^{17}$

In addition to the direct effects of a xerostomia the reduction in saliva may also compromise a patient's ability to maintain an adequate peripheral seal around a removable prosthesis.

\section{Trismus}

It is unclear what proportion of HANC patients suffer from trismus (limited mouth opening of any cause) with estimates varying from 5\% to $38 \%$. The reason for this large range is primarily due to the lack of consensus as to when a patient has restricted mouth opening, disagreement about the range of normality and variable follow up periods. The authors suggest that the normal range of mouth opening is between 35 and

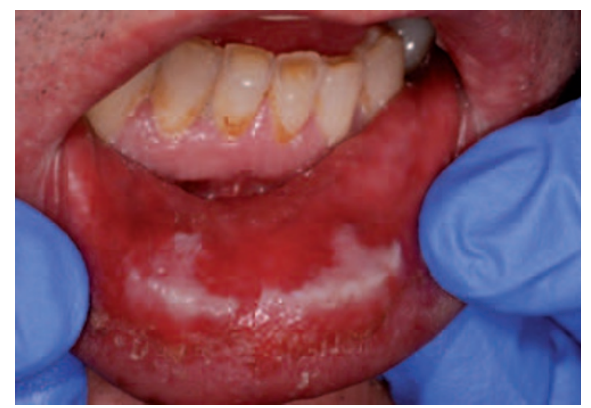

Fig. 1 Mucositis of the lower lip during radiotherapy

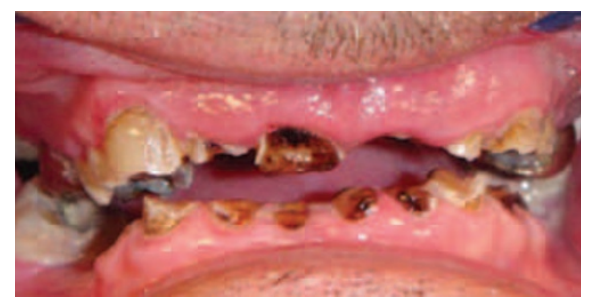

Fig. 2 A patient who sipped lemon squash and in six weeks lost his entire dentition

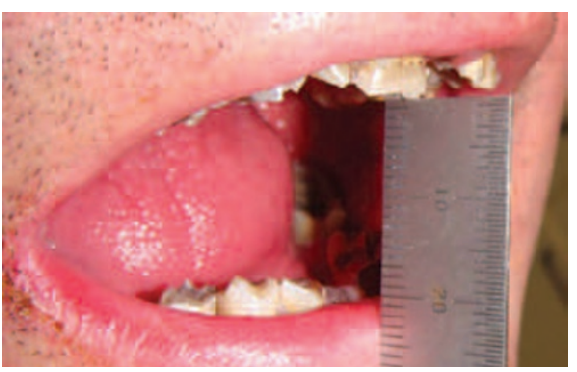

Fig. 3 Limited mouth opening of $19 \mathrm{~mm}$

$60 \mathrm{~mm}$ with significant variation within a healthy population.

Radiation damage to the TMJ and contiguous structures causes scarring and fibrosis of the muscles and ligaments leading to gradual reduction in opening beginning at about six months post-treatment. Trismus is usually seen as a late effect of radiotherapy due to the relatively slow turnover of the affected cells.

A recent UK based study found that there are several predictors of trismus in HANC patients including the size of the primary tumour, the type of surgical reconstruction and the use of radiotherapy..$^{18}$ Most significantly, radiotherapy to the TMJ and/or the pterygoid muscles may reduce mouth opening by $18 \%$ (Fig. 3). ${ }^{19}$

\section{Osteoradionecrosis of the jaws (ORNJ)}

Osteoradionecrosis has several descriptions though the most commonly accepted one in the UK is when "the irradiated bone becomes devitalised and becomes exposed through the overlying skin or mucosa 
without healing for three months, without recurrence of tumour. ${ }^{20}$

With the exception of a recurrence of cancer ORNJ is one of the worst clinical scenarios that can occur in a HANC patient. Historically it was thought to be a combination of radiation, trauma and infection though Marx suggested that ORNJ is a function of wound healing with subsequent super-infection with oral commensal bacteria. ${ }^{21}$ Thus the ORNJ disease process is now believed to affect the oral mucosa and the bone in which inadequate mucosal healing from trauma leads to soft tissue and bone necrosis (Table 3).

There are varying estimates on the incidence of ORNJ depending on the country, time of follow up and treatment modality but a recent 30 year retrospective review of 830 cases found that the overall incidence was $8.2 \% .^{22}$

The mandible accounts for approximately 95\% of all cases of the ORNJ because it has a relatively compromised blood supply compared to the maxilla and receives a larger cumulative radiation dose in most radiotherapy regimes due to the likely location of the tumour. The posterior mandible is particularly vulnerable to ORNJ and accounted for $77.5 \%$ of all cases in one study. ${ }^{23}$

Clinically ORNJ is often painless at first and in some cases may remain this way until resolution of the lesion. In severe case, however, patients may suffer intractable pain, dysaesthesia, fistulisation of the mucosa or pathological fracturing of bone (Fig. 4 and 5).

\section{The dentition}

Ionising radiation is able to cause both direct and indirect damage to the hard and soft tissues of a tooth. The reasons for the radiogenic damage to these structures are still contentious but believed to be mediated by disruption of pulpal collagen and degeneration of the odontoblastic processes causing fragility at the amelo-dentinal junction. ${ }^{24,25}$ Indirect damage to the dentition is caused by caries precipitated by changes in the saliva, taste sensation, nutrition etc as summarised in Table 4.

Radiation caries is a unique rapidly progressing disease that can be seen within several months of the onset of treatment. In severe cases it can leave a patient without a functioning dentition within a year.

Classic radiation caries is painless and
Table 4 A summary for the suggested causes of radiation caries in HANC patients

A combination of the following factors is believed to cause radiation caries: Reduction in the quantity of saliva Reduction in the quality of saliva Changes in taste perception requiring consumption of highly flavoured foods Changes in nutritional status requiring consumption of highly calorific foods Ecological changes to the oral microbiota Direct radiation damage to the dentition.

Table 5 A summary of the information required from the other members of the HANC MDT to allow a comprehensive preradiotherapy dental assessment and plan

Patient's demographic details

Scheduled time of pre-radiotherapy dental assessment

Name of surgeon

Name of clinical oncologist

Diagnosis of cancer with TNM staging

Prognosis for cancer

Type of radiotherapy prescribed ie external beam, IMRT, chemo-radiotherapy

Total cumulative dose

Fractions of radiotherapy

Field of direct radiotherapy with details of cumulative dose in Grays outside of this field

Scheduled time of commencement of radiotherapy

effects surfaces and teeth that are normally resistant to caries such as the labial surfaces of incisors. It rarely begins beneath the contact point as seen in the majority of carious lesions and is commonly seen initially in the cervical areas, which progress until the crown of the tooth becomes unsustainable under occlusal loading (Fig. 6). Often the crown then fractures at its base leaving painless carious root stumps. It is the authors' view that these asymptomatic carious roots can be maintained almost indefinitely without further caries progression or periapical pathology.

\section{The periodontium}

The supporting structures of the tooth are believed to be affected in a similar way to that of other oral tissues. The periodontium in irradiated areas of the mouth show hypocellularity, hypovascularity and increased collagen production causing fibrosis. The cementum can become totally acellular and loses its ability to repair or regenerate and Sharpey's fibres may become disorientated.

This results in an overall reduction in the periodontal tissues' ability to resist infection and can result in localised bone

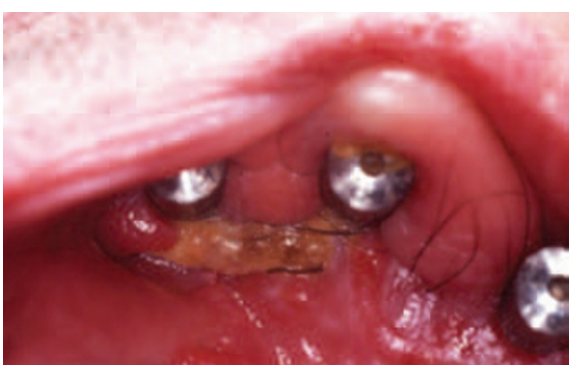

Fig. 4 Osteoradionecrosis around dental implants

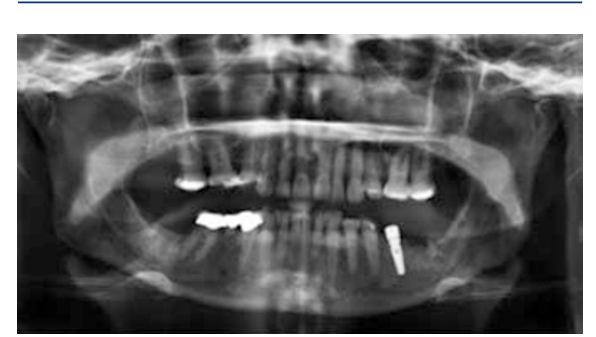

Fig. 5 Osteoradionecrosis following implant placement in irradiated bone in the lower left quadrant

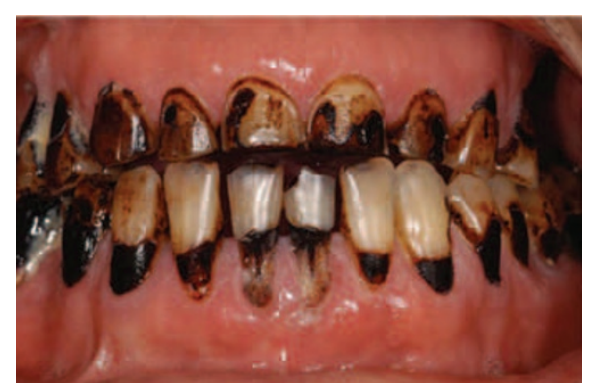

Fig. 6 Classic radiation caries on labial surfaces of teeth

destruction or even osteoradionecrosis. Furthermore, the loss of salivary protection along with an ecological shift in the oral bacteria can predispose to progressive periodontal destruction. ${ }^{26}$

\section{THE PRE-RADIOTHERAPY ASSESSMENT}

A typical pre-radiotherapy assessment request is instigated by the head and neck oncology surgeon or the clinical oncologist. The patient should ideally be referred promptly after the diagnosis of cancer has been provided by someone from the multidisciplinary team (MDT) with details of the cancer and proposed treatment (Table 5). The role of the dentist at the pre-radiotherapy stage is manifold and includes the following: ${ }^{10,27,28}$

\section{Explanation regarding the need for a pre-radiotherapy assessment and the role of the dentist in the MDT}

In a recent study of 207 Brazilian patients who were assessed before radiotherapy, 
Table 6 Important points to consider in the risk versus benefit decisions to extract or not

\section{extract teeth}

\begin{tabular}{l|l|l} 
& $\begin{array}{l}\text { Factors favouring } \\
\text { extraction }\end{array}$ & $\begin{array}{l}\text { Factors not favouring } \\
\text { extraction }\end{array}$ \\
\hline Patient's prognosis & Poor & Good \\
\hline $\begin{array}{l}\text { Likelihood of delay } \\
\text { of radiotherapy }\end{array}$ & Low & High \\
\hline Patient's wishes on extraction & Prefers to extract teeth & Prefers not to extract teeth \\
\hline Patient's dental awareness & Low & High \\
\hline Patient's dexterity & Low & High \\
\hline $\begin{array}{l}\text { Patient's wishes on } \\
\text { prosthodontic replacement }\end{array}$ & $\begin{array}{l}\text { Unlikely to desire } \\
\text { prosthodontic replacement }\end{array}$ & $\begin{array}{l}\text { Likely to desire } \\
\text { prosthodontic replacement }\end{array}$ \\
\hline Tooth prognosis & Hopeless & Excellent \\
\hline Arch & Lower & Upper \\
\hline Tooth position & Posterior & Anterior \\
\hline Strategic value of tooth & Low & High \\
\hline Likelihood of xerostomia & High & Low \\
\hline Likelihood of trismus & High & Low \\
\hline
\end{tabular}

135 patients were dentate and 72 were edentate. Of the dentate patients 120 (88.9\%) had evidence of dental pathology. The commonest pathology noted was peridontitis (63.0\%), residual roots (32.6\%) and caries $(18.5 \%) .{ }^{29}$

Although UK HANC patients rarely present with this volume of pathology their dental needs have noted to be high with regular dental attendance uncommon. ${ }^{30}$

Unfortunately, a pre-radiotherapy dental assessment is still not commonly available for HANC sufferers. The National Head and Neck Cancer Audit 2010 reported that only $8.5 \%$ of registered HANC patients had a pre-radiotherapy assessment and that this is likely to be a reflection of a lack of restorative dentists available to the HANC MDT. ${ }^{3}$ This is far short of the British Association of Head and Neck Oncologists' (BAHNO) recommendation that every patient, not just those planned for radiotherapy, should have a dental assessment. ${ }^{31}$

The MDT should be responsible for ensuring that specialised dentistry is available for all patients who require it. Expert dental assessment and treatment is important both before and after treatment, especially when radiotherapy is being considered. ${ }^{8}$

Many of these patients have complex needs that cannot be adequately met by primary care dental services. A consultant with experience in maxillofacial prosthetics and implantology is required to manage patients who need oral rehabilitation. This consultant should coordinate the dental care of patients after treatment by liaison with primary care dental practitioners. ${ }^{8}$

Experience dictates that this is often a difficult dental appointment for the patient and the clinician. The patient is often in a state of shock or denial about the diagnosis that they have just been given, which may manifests as stoicism, hysteria, aggression or even apparent apathy. Patients often later admit that they have little or no recollection of the information provided to them at this appointment or even of attending the appointment at all. This is quite understandable as the patient would have been inundated with recent information and thus the authors strongly advocate clear, concise information, directed partly at any carer and reinforced with written information and a summary letter.

The patient should firstly be advised why they are being examined by a dentist before their radiotherapy as it may seem unrelated to their diagnosis of cancer.

They should also be told that they are likely to see the dental team at least until the end of their radiotherapy regime and possibly for several years after.

A standard history should then be taken including current and recent complaints, medical diagnoses, social history and dental history. This should be supplemented by a thorough oral and dental examination, special tests to
Table 7 A summary of the oral disease prevention advice that should be provided to patients prior to the start of their radiotherapy regime

Oral disease prevention advice:

Smoking cessation advice if appropriate Reduction in the frequency of refined sugars Use of a high fluoride toothpaste eg Duraphat 5,000 ppm

Use of an alcohol free fluoride daily mouthwash Use of a fluoride tray eg with Oral-B

pro-enamel expert

Appropriate mechanical oral hygiene advice eg the modified bass technique, interdental and interspace brushes

Dry mouth relief eg Biotene Oral Balance system Saliva orthana, BioXtra, Saliveze, Xerotin or sugar-free chewing gum (NB: Glandosane should NOT be prescribed for dentate patients) Mucositis relief eg ice chips, palifermin, sucralfate.

allow definitive dental diagnoses and prognosis for individual teeth.

The patient should then be advised about the likely effects of radiotherapy to their oral and dental structures with particular reference to the sequalea outlined above.

\section{Short-term recommendations for disease control before and during radiotherapy}

The authors recommend that teeth of guarded long-term prognosis or worse should be removed if they are in the direct field of radiotherapy. In addition the authors recommend removal of teeth that are unopposed or will become unopposed after extraction of other teeth. This is primarily to prevent the need for post-radiotherapy extraction, which predisposes a patient to ORNJ. This affects 7\% of all patients who require dental extractions after they have had their jaws irradiated. This risk of ONRJ is highest for mandibular teeth in areas that have received more than 60 Gy of radiation. ${ }^{32}$

The decision should be made on an individual patient basis with careful analysis of the risks and the benefits of extraction (Table 6). Due to the subjective nature of the decision, however, there is significant variation among dentists in the UK regarding the need for pre-radiotherapy dental extractions with some favouring a more cautious approach. In patients receiving radiotherapy to the posterior part of their mouth this often means that patients will be left with a shortened dental arch, which has been shown to provide adequate function for the majority of patients..$^{33,34}$ 
Recommendations for extractions are often not well received by the patient and/ or their carer, which is very understandable. It is often perceived as adding insult to injury on a day that they have been told about a life changing diagnosis.

The patient's remaining teeth should be restored if required and any removable prostheses adjusted to allow adequate cleaning and prevent trauma to the oral tissues.

The patient should be provided prevention advice on how to maintain their oral health during and after radiotherapy as outlined in Table 7. Finally, the patient should be provided regular visits with an oral health educator and/or a dental hygienist whose primary role is to reiterate the advice given to the patient and help mitigate the effects of radiotherapy to the oral tissues.

\section{Long-term recommendations regarding oral health maintenance post-radiotherapy and any oral rehabilitation}

The patient should be reviewed three months after the cessation of radiotherapy or sooner if the patient desires. At this appointment the dentist should check the patient's understanding and compliance of the suggested oral health regime and answer any questions in relation to it. This should be followed by a thorough oral examination to evaluate any new pathology or local recurrence.

The patient is also likely to have questions relating to their long-term oral rehabilitation. This is especially the case if multiple pre-radiotherapy extractions have been prescribed of posterior teeth or the extraction of any anterior teeth.

The details of the prosthodontic rehabilitation of a post-treatment radiotherapy patient is beyond the scope of this article and we refer the reader to recent instructive articles. ${ }^{35,36}$

In general, however, many patients accept that the risks of prosthodontic rehabilitation of the posterior teeth outweigh the benefits if that area has been irradiated. The authors' experiences also suggest that irradiated patients are unlikely to wear upper and lower Kennedy Class 1 removable partial dentures.

Nonetheless, they can be fabricated to aid chewing and cosmetic function in a patient who is able to maintain effective plaque control on the prostheses and their remaining teeth.

Fixed prosthodontic rehabilitation is often complex in irradiated patients and fraught with the increased risks of failure and its sequalae. Conventional bridges are rarely indicated because of their destructive nature and the consequences of radiation caries and periodontitis on the abutments.

Adhesive bridges can be used to restore anterior teeth if the abutments are minimally restored. Alternatively four distally cantilevered bridges may be provided from the premolar teeth to give the patient two more occluding units.

Implant placement in irradiated bone should be approached with caution and are reported to have a lower chance of osseointegration. ${ }^{37}$ Nonetheless, if implants are to be used in the oral rehabilitation then many centres advocate primary placement, that is, at the time of surgery or placement soon after the end of radiotherapy. This is because the changes that occur in bone are late changes and are irreversible. The radiation has both direct and indirect effects on the micro-vasculature causing hyperaemia, endarteritis and vascular occlusion. Eventually the endothelium may atrophy with a significant reduction in osteoblast, osteoclasts and their pre-cursor cells. Thus the earlier the implant fixtures are placed in the jaws the more vascular and cellular the tissue is and the lower the likelihood of ORNJ and implant failure.

There is limited high quality research evidence on the immediate placement of implants during surgical reconstruction, however, a lower chance of osseointegration has been reported and a significant number of the integrated fixtures are likely to be suboptimally placed or unusable..$^{38,39}$

\section{CONCLUSION}

There are more than 7,000 new head and neck cancers diagnosed annually in the UK. It is one of the more common sites for cancer and there are significant regional variations in incidence in the UK.

Radiotherapy is a common treatment modality for HANCs and is the treatment of choice in areas where organ preservation is important for example, larynx and pharynx. It also plays a significant role in the post-surgical treatment of HANC to reduce recurrence or symptomatic management of patients who have untreatable disease.

Unfortunately radiotherapy affects healthy tissues as well as cancers.

In the oral cavity this may present as:

- Mucositis

- Taste disturbance

- Opportunistic infections

- Xerostomia and salivary hypofunction

- Trismus

- Osteoradionecrosis of the jaws (ORNJ)

- Caries

- Worsening periodontitis.

Dentists play an important part in the care of HANC suffers before, during and after radiotherapy. A dentist's primary role is to render a patient dentally fit before treatment by advising then of the effects of radiotherapy on the oral cavity and providing any requisite treatment. During radiotherapy a dentist's role is to maintain oral health and allow completion of treatment. After radiotherapy a dentist's role is to prevent deterioration of the dentition and provide prosthodontic rehabilitation if appropriate.

The authors would like to thank Mr Anthony Summerwill, Mrs Penny Bardsley and Ms Sara Tabiat-Pour for their clinical photographs.

1. World Health Organization. International statistical classification of diseases and related health problems. 10th ed. Geneva: WHO: 2010.

2. Parkin D M, Bray F, Ferlay J, Pisani P. Global cancer statistics, 2002. CA Cancer J Clin 2005; 55: 74-108.

3. NHS Information Centre. National head and neck cancer audit 2010, sixth annual report. Leeds: Information Centre for Health and Social Care, 2011. Online report available at http://www.hqip.org.uk/assets/NCAPOPLibrary/Head-Neck-Cancer-Audit-INTERACTIVE-2010FINAL.pdf (accessed March 2013).

4. National Services Scotland, Information Services Devision. Cancer incidence in Scotland (2010). A National Statistics Publication for Scotland. NHS Scotland, 2012. Online report available at http:// www.isdscotland org/Health-Topics/Cancer/ Publications/2012-04-24/2012-04-24-CancerIncidence-report.pdf (accessed March 2013).

5. Ouinn M, Babb P, Brock A etal Cancer trends in England and Wales, 1950-1999. London: HMSO, 2001.

6. National Cancer Institute. Radiation therapy. $\mathrm{NCl}$ dictionary of cancer terms. Online definition available at $\mathrm{http}: / /$ www.cancer.gov/ dictionary?cdrid=44971 (accessed March 2013)

7. Davies A N, Epstein J B. Oral complications of cancer and its management. Oxford: Oxford University Press, 2010

8. National Institute of Clinical Excellence. Guidance on cancer services: improving outcomes in head and neck cancer - the research evidence. London: NICE, 2004. Online report available at http://www. nice.org.uk/nicemedia/pdf/csghn_researchevidence. pdf (accessed March 2013).

9. Scottish Intercollegiate Guidelines Network. Diagnosis and management of head and neck cancer: a national clinical quideline. Edinburgh: SIGN, 2006. Online guideline available at http://www.sign ac.uk/pdf/sign90.pdf (accessed March 2013).

10. Barclay S C, Turani D. The role of the dental oncologist in the UK. Dent Update 2010; 37: 555-561. 
11. McCaul J A, Gordon K E, Clark L J, Parkinson E K. Telomerase inhibition and the future management of head-and-neck cancer. Lancet Oncol 2002. 3: 280-288.

12. Vissink A, Jansma J, Spijkervet F K, Burlage F R, Coppes R P. Oral sequelae of head and neck radiotherapy. Crit Rev Oral Biol Med 2003; 14: 199-212.

13. Clarkson J E, Worthington H V, Furness S, McCabe $M$, Khalid T, Meyer S. Interventions for treating oral mucositis for patients with cancer receiving treatment. Cochrane Database Syst Rev 2010; CD001973.

14. Worthington H V, Clarkson J E, Bryan G et al. Interventions for preventing oral mucositis for patients with cancer receiving treatment. Cochrane Database Syst Rev 2010; CD000978.

15. Maes A, Huygh I, Weltens C et al. De Gustibus: time scale of loss and recovery of tastes caused by radiotherapy. Radiother Oncol 2002; 63: 195-201.

16. Mossman K, Shatzman A, Chencharick J. Long-term effects of radiotherapy on taste and salivary function in man. Int J Radiat Oncol Biol Phys 1982; 8: 991-997

17. Dirix $P$, Nuyts $S$, Poorten $V V$, Delaere $P$, Van den Bogaert $W$. The influence of xerostomia after radiotherapy on quality of life: results of a questionnaire in head and neck cancer. Support Care Cancer 2008; 16: 171-179.

18. Scott B, Butterworth C, Lowe D, Rogers S N. Factors associated with restricted mouth opening and its relationship to health-related quality of life in patients attending a maxillofacial oncology clinic. Oral Oncol 2008; 44: 430-438.

19. Dijkstra P U, Kalk W W I, Roodenburg J L. Trismus in head and neck oncology: a systematic review. Oral Oncol 2004; 40: 879-889.
20. Lyons A, Ghazali N. Osteoradionecrosis of the jaws: current understanding of its pathophysiology and treatment. Br J Oral Maxillofac Surg 2008; 46: $653-660$

21. Marx R E. Osteoradionecrosis: a new concept of its pathophysiology. J Oral Maxillofac Surg 1983; 41: 283-288.

22. Reuther T, Schuster T, Mende U, Kübler A. Osteoradionecrosis of the jaws as a side effect of radiotherapy of head and neck tumour patients $-a$ report of a thirty year retrospective review. Int $J$ Oral Maxillofac Surg 2003; 32: 289-295.

23. Thorn J J, Hansen H S, Specht L, Bastholt L. Osteoradionecrosis of the jaws: clinical characteristics and relation to the field of irradiation. $J$ Oral Maxillofac Surg 2000; 58: 1088-1093.

24. Springer I N, Niehoff P, Warnke P H etal. Radiation caries - radiogenic destruction of dental collagen. Oral Oncol 2005; 41: 723-728.

25. Grötz K A, Duschner H, Kutzner J, Thelen M, Wagner W. [New evidence for the etiology of so-called radiation caries. Proof for directed radiogenic damage of the dentin-enamel junction. Strahlenther Onkol 1997; 173: 668-676.

26. Epstein J B, Stevenson-Moore P. Periodontal disease and periodontal management in patients with cancer. Oral Oncol 2001; 37: 613-619.

27. Joshi V K. Dental treatment planning and management for the mouth cancer patient. Oral Oncol 2010; 46: 475-479.

28. Haddard R. Multidisciplinary management of head and neck cancer. New York: Demos Medical Publishing, 2010

29. Jham B C, Reis P M, Miranda E L et al. Oral health status of 207 head and neck cancer patients before, during and after radiotherapy. Clin Oral Investig 2008; 12: 19-24.

30. Lizi E C. A case for a dental surgeon at regional radiotherapy centres. Br Dent J 1992; 173: 24-26.

31. British Association of Head and Neck Oncologists. BAHNO standards 2009. Midhurst: BAHNO, 2009.

32. Nabil S, Samman N. Incidence and prevention of osteoradionecrosis after dental extraction in irradiated patients: a systematic review. Int J Oral and Maxillofac Surg 2011; 40: 229-243.

33. Kayser A F. Shortened dental arches and oral function. J Oral Rehabil 1981; 8: 457-462.

34. Witter D J, Cramwinckel A B, Van Rossum G M Käyser A F. Shortened dental arches and masticatory ability. J Dent 1990; 18: 185-189.

35. Siddall K Z, Rogers S N, Butterworth C J. The prosthodontic pathway of the oral cancer patient. Dent Update 2012; 39: 98-100, 103-106.

36. Pace-Balzan A, Shaw R J, Butterworth C. Oral rehabilitation following treatment for oral cancer. Periodontal 2000 2011; 57: 102-117.

37. Inde S, Kopp S, Gundlach K, Konstantinović VS. Effects of radiation therapy on craniofacial and dental implants: a review of the literature. Oral Surg Oral Med Oral Pathol Oral Radiol Endod 2009; 107: 56-65.

38. Baber A J, Butterworth C, Rogers S N. Systematic review of primary osseointegrated dental implants in head and neck oncology. Br J Oral and Maxillofac Surg 2011; 49: 29-36.

39. Fenlon M R, Lyons A, Farrell S, Bavisha K, Banerjee A, Palmer R M. Factors affecting survival and usefulness of implants placed in vascularized free composite grafts used in post-head and neck cancer reconstruction. Clin Implant Dent Relat Res 2012; 14: 266-272.

\section{Erratum}

\section{Cover image (BDJ 2013; 214: No. 4)}

'Tooth art series: Tooth ring by Polly van der Glas'

In the above cover description, the artist's website should have read as follows: www.vanderglas.com.au

We apologise for any confusion caused. 